\title{
Two-Level Luck Egalitarianism: Reconciling Rights, Respect, and Responsibility
}

\author{
Johann Go ${ }^{1,2}$ (1) \\ Published online: 9 July 2020 \\ (c) The Author(s) 2020
}

\section{Introduction}

Luck egalitarianism is a broad theory of justice that emphasises the importance of responsibility (the pro-responsibility thesis), while minimising the effect of luck on people's life prospects (the anti-luck thesis). ${ }^{1}$ Luck egalitarians aim to compensate individuals for disadvantages that result through no fault of theirs, while holding responsible those who bring about their disadvantage through their own acts or omissions. There is something intuitively appealing about a theory of justice which aims to compensate people for morally arbitrary factors that influence their life prospects, while holding them responsible for the effects of their voluntary acts and omissions. After all, this seems to concur with our intuitions of fairness and responsibility. However, luck egalitarianism has been subjected to a number of criticisms. These include objections about luck egalitarianism's apparent disrespect for persons, its untenable metaphysical views about free will, and the lack of agreement on the appropriate metric to be distributed. ${ }^{2}$

In this paper, I focus on two important objections against luck egalitarianism: First, the abandonment/harshness objection, discussed by Elizabeth Anderson in her seminal article, "What Is the Point of Equality?". ${ }^{3}$ Second, the discrimination objection, which may also be related to the problem of innocent choice. ${ }^{4}$ Several

\footnotetext{
1 Richard J. Arneson, "Luck Egalitarianism Interpreted and Defended," Philosophical Topics 32, no. 1-2 (2004): 1-20.

2 Elizabeth Anderson, "What Is the Point of Equality?" Ethics 109 (1999): 287-337; Samuel Scheffler, "What is Egalitarianism?" Philosophy and Public Affairs 31, no. 1 (1999): 5-39; Samuel Scheffler, "Choice, Circumstance, and the Value of Equality," Politics, Philosophy and Economics 4, no. 1 (2005): 5-28; and Jonathan Wolff, "Fairness, Respect, and the Egalitarian Ethos," Philosophy and Public Affairs 27, no. 2 (1998): 97-122.

3 Anderson, "What Is the Point of Equality?" 287-337.

4 Nir Eyal, "Egalitarian Justice and Innocent Choice," Journal of Ethics and Social Philosophy 2, no. 1 (2006): 1-18.
}

Johann Go

Johann.Go@worc.ox.ac.uk; Johann.Go@politics.ox.ac.uk

1 Department of Politics and International Relations, University of Oxford, Oxford, UK

2 Worcester College, University of Oxford, Walton Street, Oxford OX12HB, UK 
influential responses have recently been offered in the luck egalitarian literature against these two objections, which will be the subject of my discussion in the first part of this paper. In the second part of the paper, I take inspiration from a number of these responses to outline a two-level account of luck egalitarianism.

The general structure of this paper will be as follows: First, I outline the basic tenets of luck egalitarianism and discuss two of Elizabeth Anderson's well-known objections. One objection is concerned with leaving in dire straits those responsible for their own misfortune. The other is concerned with holding people responsible for the effects of their voluntary acts which we nonetheless regard as morally neutral or praiseworthy, such as the disadvantage that comes from choosing to be an unpaid caregiver or disclosing one's sexual orientation. Second, I explore seven responses to the harshness and discrimination objections from the literature: (i.) bite the bullet; (ii.) rights and duties; (iii.) sufficiency/basic needs/domain response; (iv.) qualified harshness/adjusted responsibility; (v.) compulsory insurance; (vi.) agent identity/dynamic luck egalitarianism; and (vii.) innocent choice, reasonable avoidability and modified luck egalitarianism. It is important to note that some responses are intended to address only one of the objections, while some are intended to address both. It is in this spirit that the responses are evaluated. ${ }^{5}$ While I will argue that these individual accounts cannot, for the most part, provide a convincing response to the objections, they nonetheless offer important insights for the construction of a more plausible luck egalitarian theory.

Third, I take inspiration from these accounts to outline a two-level account of luck egalitarianism which combines a plurality of morally relevant factors and is sensitive to rights and duties, but one which is still distinctly responsibility-sensitive. The first level of the two-level account guarantees the provision of fundamental rights and basic needs, irrespective of responsibility. The second level governs the distribution of more general goods and is sensitive to responsibility. I draw on John Rawls' influential two concepts of rules idea to show that the luck egalitarian justifications that go into designing the first level of the theory do not have to be used in the practice and application of that same theory. I also highlight what I shall call the Fact of Inherent Normativity built into any luck egalitarian account of justice, which enables the consideration of a host of independent ethical principles while remaining a consistent luck egalitarian. The justification for the separation of the two tiers is derived from core luck egalitarian principles.

\footnotetext{
5 For example, as an anonymous reviewer for the journal aptly points out, the 'compulsory insurance' response is intended as a response to the harshness objection. It may be uncharitable, therefore, to evaluate whether it works with regards to the discrimination objection. However, I think that if the compulsory insurance response fails to respond to the discrimination objection, this itself highlights something important (namely, that a resource-based insurance response is not enough to neutralise the effect associated with discrimination).
} 


\section{Anderson's Harshness and Discrimination Objections}

One of the most well-known critics of luck egalitarianism is Elizabeth Anderson. ${ }^{6}$ In an influential article, Anderson advances a number of criticisms of luck egalitarianism including the 'abandonment of negligent victims' ${ }^{7}$ The abandonment of negligent victims objection, also referred to as the harshness objection, is directed primarily at luck egalitarianism's pro-responsibility thesis. In one of Anderson's examples, an uninsured driver is driving recklessly, causes an accident and is badly injured. According to Anderson, a luck egalitarian is not required to assist the person for his or her injury and should let the person die, because they were responsible for their own predicament.

Consider the same argument in standard form, derived from Carl Knight's interpretation of Anderson's abandonment critique ${ }^{8}$ :

(P1): A plausible theory of justice will not abandon individuals to experience severe and/or very harmful results.

(P2): Luck egalitarianism will abandon individuals to experience severe and/or very harmful results.

(C): Therefore, luck egalitarianism is not a plausible theory of justice.

Another objection is what I shall call the discrimination objection. This is similar to another of Anderson's critiques, which she calls the vulnerability of dependent carers objection. The objection highlights a potential counter-intuitive conclusion that those who take on certain kinds of jobs that disadvantage them in the market economy are justifiably made worse-off. ${ }^{9}$ For example, a mother who makes the decision to have children, or to stay at home and care for her children rather than performing a wage-based job, puts herself at a distributive disadvantage voluntarily. The discrimination objection is inspired by Anderson's critique, but it is inherently broader in scope. The discrimination objection covers actions beyond vulnerable caretakers, such as the case of a gay man who voluntarily decides to come out of the closet and subsequently experiences discrimination. Given that the action was voluntary and the effects reasonably foreseeable, the luck egalitarian may dismiss the resultant disadvantage as being a concern of justice. The discrimination objection can be structured as follows:

(P1): Luck egalitarianism holds that those responsible for their acts/omissions should have to bear its distributive effects.

(P2): A person who discloses his gay sexual orientation to his work colleagues does so deliberately and within the framework of a responsible act.

\footnotetext{
6 Anderson, "What is the Point of Equality?", 287-337.

7 Anderson, "What is the Point of Equality?" 289; 295-298.

8 Carl Knight, “Abandoning the Abandonment Objection," Res Publica 21, no. 2 (2015): 119-135, at p. 120.

9 Anderson, "What is the Point of Equality?" 296-298. See, also, Anderson's discussion of disdain and occupational discrimination in the same paper.
} 
(C1): Therefore, according to luck egalitarianism, the gay person should have to bear the distributive effects of disclosing his gay identity (including, for example, workplace discrimination or the resultant financial disadvantage).

(P3): $\mathrm{C} 1$ is implausible and unjust.

(C2): Therefore, luck egalitarianism is implausible and unjust.

The general structure of the objection takes the form of a reductio ad absurdum logical structure. The example used for Premise 2 can be substituted with other congruent cases, such as a person disclosing her minority religious beliefs, despite being aware of the disadvantage she may experience as a result of doing so. Premise 2 may also be replaced, for example, with the scenario of a selfless person rushing into a burning house to save a child and, in doing so, experiencing severe disadvantage as a result of personal loss or injury. ${ }^{10}$ In undertaking a voluntary but morally praiseworthy act, it may transpire that the rescuer is not entitled to any distributive assistance because they were responsible for the act and are therefore required to bear its distributive impact. While risky heroic acts may fall within a similar theoretical space occupied by the discrimination objection (despite these being different types of objections), I am primarily concerned in this paper with the discrimination objection. This is because there seems to be something deeply troubling about an egalitarian theory of justice that fails to uphold the importance of an individual's moral status and respect in a way that is different to simply lacking an adequate response to supererogatory acts. ${ }^{11}$ While the discrimination objection strikes me as one of the most powerful objections against luck egalitarianism, it has remained under-addressed in the luck egalitarian literature. It is paramount to the luck egalitarian project, it seems to me, that a plausible response be available to counter this objection. Combined with the harshness objection, these problems relate to the proresponsibility component of luck egalitarianism which has come under the most scrutiny.

\footnotetext{
${ }^{10}$ Nir Eyal, "Egalitarian Justice and Innocent Choice," Journal of Ethics and Social Philosophy 2, no. 1 (2006): $1-18$, at pp. 3-4.

${ }^{11}$ The discrimination objection remains under-addressed in the contemporary luck egalitarian literature. For some notable exceptions, see: Timothy Hinton, "Must Egalitarians Choose Between Fairness and Respect? Philosophy and Public Affairs 30, no. 1 (2001): 72-87; Seana Shiffrin, "Egalitarianism, Choice-Sensitivity, and Accommodation," in Reason and Value: Themes from the Moral Philosophy of Joseph Raz edited by R. Jay Wallace, Phillip Pettit, Samuel Scheffler, and Michael Smith (Oxford: Oxford University Press, 2006): 270-302; Zofia Stemplowska, "Making Justice Sensitive to Responsibility," Political Studies 57, no. 2 (2009): 237-259; Huub Brouwer and Thomas Mulligan, "Why Not be a Desertist? Three Arguments for Desert and Against Luck Egalitarianism," Philosophical Studies 176 (2019): 2271-2288; and Jens D. Thaysen and Andreas Albertsen, "When Bad Things Happen to Good People: Luck Egalitarianism and Costly Rescues," Politics, Philosophy and Economics 16, no. 1 (2017): 93-112.
} 


\section{Luck Egalitarian Responses}

A satisfactory response, I shall argue, must encompass all three cardinal values essential to an egalitarian theory of justice: respect, rights, and responsibility. I will address these three cardinal principles in the constructive part of this paper but, in the meantime, I will work with the assumption that these three desiderata must be present for a response to be satisfactory. I consider these desiderata only indirectly in my evaluation of the responses, but I hope it is nonetheless clear that they are the driving normative principles behind whether or not we ought to regard a response as adequate.

\subsection{Response 1: Bite the Bullet}

One initial response to the discrimination objection we ought to consider is to bite the bullet by denying the implications. That is to say, deny Premise 3 and support the Sub-Conclusion (C1) that the gay man does indeed need to bear the reasonably foreseeable distributive consequences of the act of disclosing his sexuality. However, this response is unlikely to be convincing, given our considered judgements on this topic. If we promote a 'bite the bullet' response, we would have to tolerate other congruent cases of being held responsible for our voluntary choices on the spurious grounds that society mistakenly disapproves. We should therefore discard this as a reasonable or plausible response to the discrimination objection.

The bite the bullet response can also be offered as a reply to the harshness objection. Eric Rakowski, for example, can be said to hold this general view. ${ }^{12}$ Rakowski argues that once insurance is available, those who do not insure should be left on their own to suffer the misfortunes that arise from their own negligence. ${ }^{13}$ I will return to the issue of how we ought to respond to the issue of recurrent negligence, and whether justice requires that we leave these people to their dire straits, in the final section of this paper. In the meantime, however, I will accept the prima facie view that the harshness objection against luck egalitarianism is in need of a response.

\subsection{Response 2: Rights and Duties}

One way for luck egalitarians to respond to the harshness and discrimination objections is to stipulate that luck egalitarianism operates in accordance with a system of rights so its distributive implications can be overridden if it is seen to breach individuals' rights. ${ }^{14}$ This approach is exemplified by Zofia Stemplowska's earlier work, where she argues that there are some goods a person should.

\footnotetext{
12 See: Eric Rakowski, Equal Justice (New York: Oxford University Press, 1991), 78-81.

13 Rakowski, Equal Justice, 79.

14 Zofia Stemplowska, "Making Justice Sensitive to Responsibility," Political Studies 57, no. 2 (2009): 237-259.
} 
...never be deprived of, no matter what. For example, however imprudent, reckless or foolish one's choices, a person should never be denied equal treatment before the law simply because he or she was imprudent, reckless or foolish. $^{15}$

Stemplowska subsequently goes on to claim, however, that an imprudent mountain climber who gets injured as a result of negligence may not have a claim to assistance if the costs to society are excessively high:

. . the conclusion that the mountain climber must be rescued no matter what, as a matter of egalitarian justice, is implausible . . to deliver what the objection asks for - unconditional assistance for all in thoroughly bad outcomes - we would either have to go against our understanding of a fair balancing of people's interests or stop being egalitarian. ${ }^{16}$

This makes Stemplowska's account slightly confusing, vis-à-vis what role rights really play in constraining the objections to luck egalitarianism. Some of the ambiguities in her account include when rights are considered to be absolutely binding, as in the case of the right to equality before the law; what kind of rights should be considered in the first place (for example, whether rights to food, shelter or employment are such rights); and how rights are to be balanced with other morally relevant considerations (such as consequences, freedom, security, and the impact on others). Indeed, Stemplowska holds the position that we should bite the bullet on some of the implications of the harshness objection on grounds independent of rights considerations. The dilemma, given the present articulation of Stemplowska's account, is this: Either Stemplowska must accept a stronger account of rights that can override fundamental luck egalitarian considerations, or she must accept the implications of the harshness and discrimination objections.

In the first scenario, luck egalitarian principles may simply become redundant, if the scope of rights is sufficiently broad. For example, if we accept that there are unconditional rights to food, housing, health care, and employment, it is hard to see how luck egalitarianism could provide distributive guidance in any meaningful way, given that rights considerations would then already adjudicate the distribution of most important goods. In the second scenario, it poses the question of why rights should even be considered in the luck egalitarian framework if we are subsequently instructed to bite the bullet in cases where the harshness objection comes up. If the purpose of rights is to constrain luck egalitarian's propensity to tolerate discrimination as a result of people's voluntary choices and abandon negligent individuals, they must have at least some substantive role to play.

One possible response is to advance a 'pluralism caveat'. This is the claim that rights are only one of many things that could govern a luck egalitarian distribution, and that other morally relevant factors, such as consequences, security, freedom, and third-party effects should also be considered. This response is puzzling for a number

15 Stemplowska, "Making Justice Sensitive to Responsibility," 254.

16 Stemplowska, "Making Justice Sensitive to Responsibility," 253. 
of reasons. First, Stemplowska identifies an example of a right that can never be violated irrespective of a person's foolishness or imprudence, namely, the right to equal treatment before the law. To then advance a pluralism caveat would be to defeat the absolute nature that Stemplowska appears to grant to this right. Second, if we are to grant rights a weak role, we become trapped in the same dilemma identified beforehand. If we grant rights a strong role, it challenges the uniqueness and distributiveguiding purpose of luck egalitarianism. The challenge for Stemplowska, therefore, is to first, articulate a basic account of which rights and duties can constrain luck egalitarianism and which ones cannot, and second, to justify these in a manner consistent with the core principles of responsibility-sensitive justice. I propose a method for doing so in the final section of this paper.

\subsection{Response 3: Sufficiency, Basic Needs, and the 'Domain' Response}

Another theorist who is arguably influenced by the significance of rights is KokChor Tan, who proposes limiting the 'domain' of distributive justice only to goods above the sufficiency threshold. ${ }^{17}$ Individuals below the threshold of sufficiency, howsoever defined, have a right to have their needs met independently of luck egalitarian principles and irrespective of their responsibility for being in such situations. ${ }^{18}$ The principle that ought to govern the distribution of goods necessary for sufficiency, Tan argues, is 'humanitarianism'. ${ }^{19}$ I consider this account a form of rights-constrained luck egalitarianism because it is de facto committed to the view that people have a right to certain basic needs no matter what. The right to the goods necessary to reach the threshold of sufficiency trumps luck egalitarian considerations of responsibility.

Recall the case of Anderson's reckless and uninsured motorist who subsequently has an accident. Tan's domain response can escape the harshness objection because the injured motorist has now dropped below the level of sufficiency. The motorist has a right to medical treatment and assistance to bring her up to the threshold of sufficiency, which trumps luck egalitarian considerations. The 'trumping' mechanism is built into the domain response, whereby luck egalitarian considerations are superseded in cases where people's basic needs are violated regardless of responsibility. "Principles of basic rights or human decency can require that a person deprived of basic needs be rescued or assisted, even if the deprivation was due to her own imprudence." 20

\footnotetext{
17 Kok-Chor Tan, Justice, Institutions, and Luck: The Site, Ground, and Scope of Equality (Oxford University Press, 2012); Kok-Chor Tan, “A Defence of Luck Egalitarianism,” Journal of Philosophy 105, no. 11 (2008): 665-690; and Kok-Chor Tan, "Luck, Institutions, and Global Distributive Justice: A Defence of Global Luck Egalitarianism,” European Journal of Political Theory 10, no. 3 (2011): 394-421. Segall may be said to have a kind of domain-type response too. See: Shlomi Segall, Health, Luck and Justice (Princeton: Princeton University Press, 2009).

18 Tan, Justice, Institutions, and Luck, 100-120.

19 Tan, Justice, Institutions, and Luck, 120.

20 Tan, "A Defence of Luck Egalitarianism," 676, my emphasis.
} 
Notice, however, that Tan's domain response alone cannot deal adequately with the discrimination objection if these people are already above the threshold of sufficiency. Let us add more detail to the hypothetical case of the gay man voluntarily coming out of the closet at work to illustrate this point. Assume that the gay man is a wealthy and successful business executive who has a nice house, a stable marriage, and a good state of health and wellbeing. By disclosing his sexuality at work, he disadvantages himself, with some homophobic board members vetoing his promotion to the position of Deputy Chief Executive. He also becomes the recipient of occasional homophobic remarks. Assume that he was aware of the board members' homophobic attitudes, but chose to disclose his sexuality nonetheless. In this situation, Tan's response of limiting luck egalitarianism's domain and scope to those above the level of sufficiency may be futile. The gay man has been disadvantaged, but is still well above any reasonable level of sufficiency, with a well-paid job, a fulfilling social life, and good access to material resources. Tan's rights-motivated domain response, on its own, cannot respond to this situation in line with our considered judgements. It would have to accept that the gay man should be held responsible for the distributive impacts of his voluntarily choice or, at the very least, that the distributive impact of his actions should be subject to luck egalitarian considerations prior to any justice-based rectification. ${ }^{21}$

One potential escape for Tan's rights-motivated domain solution is to include freedom from unjust discrimination as part of the threshold of sufficiency. However, this approach falls prey to a recurring problem - namely, rights taking up too central a role such that the luck egalitarian principles simply become idle. This response also highlights an area of ambiguity in Tan's account, since he does not provide an answer to what the threshold of sufficiency ought to be (beyond the vague allusion to 'humanitarianism'). This is akin to Stemplowska not providing a guideline for which rights ought to be considered as trumping luck egalitarian considerations. Because I have argued that Tan's domain response is a de facto rights-derived constraint on luck egalitarianism, many of the critiques I levied against Stemplowska's account is also applicable here. To continue relying upon the domain response to the harshness objection, the Tan-type luck egalitarian must either define the sufficiency threshold in such a way that it essentially renders the luck egalitarian component of the theory redundant when it comes to matters of justice, or define it so loosely that proponents may as well rely on another mechanism to constrain luck egalitarianism's unacceptable implications.

Put another way, if almost all our considered judgements about justice and distribution can be captured by rights talk alone (noting that the domain response is one method for emphasising the significance of rights), what is the point of luck egalitarianism? And if we demarcate the domain such that our objections about the harshness or discrimination objections cannot be satisfactorily met, what is the point

\footnotetext{
${ }^{21}$ Even if homophobic discrimination were to cause him to drop below the level of sufficiency, Tan's account would support lifting him up again independently of the discrimination. However, this response would be motivated by a concern for his basic needs rather than in direct response to the homophobic discrimination.
} 
of luck egalitarians bringing in the concept of rights? Tan's account may be able to respond in other ways to these objections, but it would not be via his domain response or through the consideration of rights.

One way Tan could respond is to highlight the institutional scaffold for his luck egalitarian account. According to Tan, the proper subject of luck egalitarian distribution is the institutional arrangements that translate brute facts into advantages to disadvantages for people's life prospects. ${ }^{22}$ For example, it is not the fact of being gay that makes it a subject of luck egalitarian justice, but the fact that institutions turn this brute fact into a source of disadvantage. Notice, however, that this cannot capture the entire objection about voluntarily disclosing one's sexuality. Institutional luck egalitarianism is critical of institutions translating matters of brute luck into (dis)advantages. However, voluntarily choosing to disclose one's sexuality is not a matter of brute luck; it is generally a conscious decision. ${ }^{23}$ It remains unclear, then, how Tan's institutional account would evaluate the resultant disadvantage.

The institutional response is itself far more normatively influenced than Tan seems to realise. This point matters to Tan's account because his primary claim is that luck egalitarianism is the justificatory principle for equality. It is institutional luck egalitarian principles, Tan argues, that grounds our moral commitment to distributive equality over and above the level of subsistence. ${ }^{24}$ Luck egalitarianism, according to Tan, is not a substantive account of distributive justice (i.e. it is not a guide for how or what to distribute), but only a grounding principle to specify why distributive equality matters. On this view, luck egalitarianism's plausibility is derived from its unique ability to ground a commitment to distributive equality. ${ }^{25} \mathrm{It}$ appears, however, that rights and other moral considerations have a significant role in Tan's motivations about his institutional account.

Consider a hypothetical scenario: Wolfgang happens to be born into a Nazisympathising family. From a young age, he was brain-washed to hold racist views against Jews. Wolfgang did not choose his family, nor did he have any control over his racist brainwashing. The society's institutions are set up in such a way that Nazisympathising individuals are disadvantaged. For example, Nazi-sympathisers have greater difficulty finding employment and thriving socially in this society. Ought the institutional luck egalitarian be concerned that our institutional arrangement translates Wolfgang's circumstances of birth into disadvantage?

One plausible response is to argue that societal institutions should respond with education to challenge Wolfgang's brainwashed views. However, this is a distraction from my challenge to Tan's account. The challenge for Tan is to articulate why certain institutional arrangements that translate brute fact into disadvantage are matters for luck egalitarian distribution while others are not. It seems some

\footnotetext{
22 Tan, Justice, Institutions, and Luck, 127; 187.

23 Being gay is arguably not a choice one makes, even if disclosing it is. However, the act of disclosure matters, since it is often the necessary condition that makes others aware of one's identity, and the precursor for distributive disadvantage.

24 Tan, "A Defence of Luck Egalitarianism," 674.

25 Tan, "A Defence of Luck Egalitarianism," 674.
} 
institutionally-sanctioned disadvantage warrant luck egalitarian concern but not Wolfgang's. Why is this so? It cannot simply be the luck-choice distinction, assuming we think Wolfgang is not responsible for his racist upbringing. It seems to me that what is driving our intuitions in these instances is the presence of rights and other moral principles. The fact that the Nazi-sympathiser's disadvantage does may not warrant institutional reform or luck egalitarian compensation is because we do not believe he has an existing right to be racist. ${ }^{26}$ On the other hand, the gay man has a right not to be unjustly discriminated against, and this is what drives the institutional luck egalitarian intuition. If the institutional luck egalitarian mandates some kind of egalitarian transfer to compensate for an institution's arrangement disadvantaging someone, or if it mandates that institutional reform be done, it is because there is already a prior notion that one has a right to those things. Tan's account cannot take into account these intuitions unless he incorporates a clearer idea of rights or, at the very least, the consideration of some independent ethical standard.

Consider another hypothetical scenario: Sarah, as a result of a (brute luck) accident, has managed to amputate one of her fingers. Assume that the machine, which amputated her finger, did so painlessly and, because of the heat, has actually sealed the stub of her amputated finger. There is therefore no immediate or ongoing clinical risk. She lives in a deeply Buddhist community, where they spend an overwhelming portion of their time in meditation and solitary reflection. Having fingers is not a requirement for success or respect in her society. Rather, her society's institutions place high respect upon merely sitting in stillness and meditating. Having an amputated finger therefore places Sarah in no significant disadvantage. Should the institutional luck egalitarian compensate Sarah for her brute luck, even if the institutional arrangement means there is no real impact on her life's prospects?

I have purposely set up the above scenario to correspond to something we intuitively think is bad but not so harmful that it drops her below the level of sufficiency. It seems the institutional luck egalitarian may nonetheless feel that we owe the unfortunate victim some compensation for her brute luck accident, independently of the institutional arrangements not disadvantaging her life's prospects. If this is so, it seems that Tan is not relying upon luck egalitarian principles so much as being influenced by a pre-existing right to bodily integrity, for example. Biting the bullet and accepting the implications of the institutional luck egalitarian position is also a possibility, though this may reduce the appeal of Tan's account when weighed with our considered judgements. ${ }^{27}$

\footnotetext{
${ }^{26}$ Some people may be willing to accept the full implications and argue that Wolfgang does indeed deserve compensation for holding Nazi views that disadvantage him in society. I suspect (and work with the assumption), however, that these people are in the minority.

27 I acknowledge, of course, that Tan may not be concerned at all with scenarios where no institutional disadvantage arises. Nonetheless, it suffices for my point here to appeal to the reader's considered judgements about whether such cases of bad brute luck (even without the resultant institutional disadvantage) is something we are willing to tolerate. If I am right that most people would not agree with tolerating Sarah's amputated finger at the bar of justice, then it challenges the general plausibility of the institutional luck egalitarian response.
} 
The purpose of this section on Tan's account is to demonstrate a number of claims: First, Tan's domain response, insofar as it is a de facto rights-constrained approach, is open to some of the same implications as Stemplowska's account. It is faced with the dilemma of either granting rights a strong role, such that luck egalitarian considerations become redundant due to over-determination, or not granting rights a strong enough role, such that it throws into question why it is even raised as a response to the harshness and discrimination objections. Second, Tan's institutional scaffold is motivated by a host of background luck egalitarian-independent ethical and rights-based motivations, as demonstrated through the two basic thought experiments. Third, Tan's proposal of limiting distributive justice considerations only to a specific domain may be too quick and ad hoc. Relying upon mere humanitarian intuitions is not sufficient. No real justification is offered for such a move, and there is little clarity around what level the threshold of sufficiency should be set at.

\subsection{Response 4: Qualified Harshness Objection and Adjusted Responsibility}

Kristin Voigt argues in favour of a qualified harshness objection to take into account the fact that even apparently fully voluntarily actions are seldom cases of pure option luck. ${ }^{28}$ Voigt argues that the brute and option luck distinction is seldom clearcut, such that even fully voluntarily choices will have elements of brute luck and therefore demand at least partial compensation in the real world. ${ }^{29}$ Voigt proposes reformulating the Harshness Objection to take into account this fact, such that a very high threshold is required to meet it:

When an agent, as a matter of pure option luck - i.e., when unequal brute luck did not affect the choice the agent faced (for example by limiting the range of options available or by increasing the cost of particular options), and when the agent failed to act in accordance with a standard of reasonableness that was appropriately individuated to take account of the effects of unequal brute luck - ends up in desolate circumstances, then luck egalitarianism requires that we do not provide assistance to this agent, even if there are no opportunity costs associated with the provision of such assistance. ${ }^{30}$

One problem with this response, which Voigt herself acknowledges, is that it leaves open the possibility that partial compensation will not be enough satisfy our objections. There may be cases where partial compensation of those in dire straits may not be enough to avoid the catastrophic outcomes of their partially voluntary acts. Partial compensation, in these instances, would not be able to escape the harshness objection. While the discrimination objection is not the primary subject of Voigt's article, it is worth analysing how she would respond to the gay man who disadvantages himself by voluntarily coming out of the closet. One of Voigt's response could

\footnotetext{
${ }^{28}$ Kristin Voigt, "The Harshness Objection: Is Luck Egalitarianism Too Harsh on Victims of Option Luck?” Ethical Theory and Moral Practice 10, no. (2007): 389-407.

29 Voigt, "The Harshness Objection," 389-407.

30 Voigt, "The Harshness Objection," 402.
} 
be that the gay man's decision to disclose his sexuality was not fully the result of option luck and motivated by brute luck factors such as his internal identity as a gay man compelling him to disclose the fact. The gay man, then, is entitled at least to partial compensation given that his voluntary action was not the result of pure option luck.

This response, however, arguably fails to capture our intuitive objections to the discrimination objection. The disadvantages the gay man experiences as a result of such a voluntary act are seen to be objectionable because they stem from unjust societal attitudes and because we think that he has an existing right to freely and openly express his sexual identity free from discrimination, in a way Wolfgang the racist Nazi-sympathiser does not. These considered judgements about rights and respect cannot be captured even with considerations about the differential prevalence of brute and option luck in individuals' acts/omissions. What Voigt's insights demonstrate, however, is that the construction of our general luck egalitarian theory should be designed to take into account difficulties with applying those same principles in the non-ideal real world. I expand on the significance of this issue in the second part of this paper.

\subsection{Response 5: Compulsory Public Insurance}

One important response available to mitigate the harshness objection is the presence of compulsory public insurance. Carl Knight argues that luck egalitarianism has existing mechanisms within it to promote public insurance, which in turn means we do not have to leave negligent people in dire straits. ${ }^{31}$ While the compulsory insurance argument is a promising policy solution, it is not itself a self-standing justification to the harshness (or discrimination) objections for the reasons that follow.

First, as Knight himself recognises, compulsory insurance must itself be justified on the basis of further argument. For example, simply stating that compulsory insurance could respond to the harshness objection (without any further reasoning) is somewhat analogous to simply stating that we can respond to the harshness objection by unconditionally rescuing people. It is not, on its own, a luck egalitarian solution. The justification for why a compulsory insurance scheme ought to exist needs to be further developed. Knight acknowledges this important fact through his exploration of a number of different justifications that could ground compulsory insurance.

Second, even once compulsory insurance has been justified on luck egalitarian grounds, there will be further questions around the principles that ought to govern its distribution in practice. Consider the case of public health care. Compulsory public insurance or mandatory social insurance is a method to pool resources and thereby a means to offer public insurance to the populace to protect against ill health. However, having such a system of public insurance does not make issues of resource allocation disappear. From the pool of public insurance funds, we are still

\footnotetext{
31 Carl Knight, "Abandoning the Abandonment Objection: Luck Egalitarian Arguments for Public Insurance," Res Publica 21, no. (2015): 119-135.
} 
faced with the problem of what to fund, who to fund, and in what circumstances, $a s$ a matter of justice. ${ }^{32}$

The compulsory insurance argument, then, is an important response to the harshness objection but, to retain its luck egalitarianism, it must be supported by luck egalitarian reasons for why it should exist and, once it exists, principles for how to distribute the pool of public funding on luck egalitarian grounds. This issue is not insurmountable, but it shows that the compulsory insurance argument needs further supporting reasoning to make it compatible with luck egalitarianism. In the constructive section of my paper, I sketch a preliminary account for what kind of principles and reasons can be advanced in support of such a scheme to retain its luck egalitarianism.

It may also worthwhile to note how the public insurance response would respond to the discrimination objection. As with previous responses, it is not clear how our considered judgements about minority rights and discrimination can be captured by the provision of public insurance. To be clear, I acknowledge that the compulsory insurance argument is intended to diffuse the harshness objection rather than the discrimination objection. However, the fact that it cannot be seen as a satisfactory response to the discrimination objection highlights something important about the nature of luck egalitarian justice; namely, that the metric to be distributed cannot merely be resources, since the gay man's disadvantage (in our discrimination objection example) is not merely his damaged financial position. I return to the significance of this latter point in the constructive section of this paper.

\subsection{Response 6: Agent Identity and Dynamic Luck Egalitarianism}

Another interesting approach to respond to the harshness objection is what we might call 'dynamic luck egalitarianism' or the agent-identity response. Patrick Tomlin argues that a 'dynamic luck egalitarian' approach means that we should be sensitive of the temporal standpoint at which a certain act is committed, and that the agent's identity over time can alter how we attribute responsibility to her. ${ }^{33}$ Tomlin's dynamic luck egalitarian account:

“( a) recommends that we assess responsibility for a choice-based inequality at the time at which we are trying to assess the justness of the inequality, rather than at the time of choosing; and (b) accepts that responsibility may diminish as people change." 34

Knight succinctly phrases the agent identity response as follows:

\footnotetext{
32 Norman Daniels, Just Health: Meeting Health Needs Fairly (New York: Cambridge University Press, 2008). To take a recent example, the debate around whether gender reassignment surgery should be publicly funded requires further reasoning about justice, even if a public insurance/public taxation system of healthcare already exists. See Johann Go, "Should Gender Reassignment Surgery be Publicly Funded?" Journal of Bioethical Inquiry 15, no. 4 (2018): 527-534.

33 Patrick Tomlin, "Choices, Chance and Change: Luck Egalitarianism Over Time," Ethical Theory and Moral Practice 16, no. (2013): 393-407.

34 Tomlin, "Choices, Chance, and Change," 394.
} 
"It may be that the persons that result from the traumatic events typically described in abandonment cases rarely, if ever, stand fully in the relation that matters to their earlier selves, in which case assistance should be forthcoming." 35

I do not find the agent identity or the significance of the metaphysical case convincing. Consider, for example, Marc Fleurbaey's hypothetical motorcyclist, Bert, who enjoys riding a motorcycle without a helmet to feel the wind on his hair. ${ }^{36}$ Let me now continue and frame the scenario slightly differently. As a direct result of Bert's carelessness and negligence, he is involved in an accident and sustains a serious head injury. He sustains retrograde amnesia and develops a new personality. He has no sense of psychological continuity with his prior self and is, for all intents and purposes, a 'new person'. ${ }^{37}$ However, the fact that he is now a 'new person' was brought about directly by his negligent risk-taking. Tomlin and Knight, on the agent identity approach, would have to evaluate Bert's responsibility after the incident when he is a 'different' person. It may then transpire that, despite acting negligently to bring about his head injuries and therefore his 'new personality', he should not be held responsible for the distributive impact of his negligent choices. Such an approach arguably runs contrary to luck egalitarian principles of responsibility.

Knight is therefore in a dilemma. He must either (1) bite the bullet and accept that agent identity (beyond a minimalist pragmatic view) is not that important, or (2) abandon his luck egalitarian commitments in cases where there is an important change of identity in the person (which Knight himself states is in virtually all cases of abandonment). I analyse the issue of underlying ethical motives being behind many luck egalitarian principles in the constructive part of my discussion.

\subsection{Response 7: Innocent Choice, Reasonable Avoidability and Modified Luck Egalitarianism}

Another group of responses is to move luck egalitarianism towards a more moralised perspective, whereby actions are evaluated according to some external normative standard. Nir Eyal, for instance, argues in favour of a 'modified luck egalitarian' position that takes seriously the normative status of particular acts being evaluated. ${ }^{38}$ In a thought experiment, Eyal presents the case of Hero, a person who is injured while heroically but voluntarily rescuing a baby from a house fire. According to what Eyal calls standard luck egalitarianism, Hero's fate would be dismissed as arising entirely from bad option luck. ${ }^{39}$ The proposed solution is to hold people responsible only for their "culpable choices", which are actions that are "at least

\footnotetext{
35 Knight, "Abandoning the Abandonment Objection," 130.

36 Marc Fleurbaey, "Equal Opportunity or Equal Social Outcome?" Economics and Philosophy 11 (2011): 25-55, at p. 40.

37 For a discussion on the significance of psychological continuity to personal identity, see Derek Parfit, Reasons and Persons (Oxford: Clarendon Press, 1984).

38 Eyal, "Egalitarian Justice and Innocent Choice," 3-6.

39 Eyal, Egalitarian Justice and Innocent Choice," 4.
} 
somewhat morally wrong". ${ }^{40}$ Given that the option luck choice to enter the burning house to rescue a child is not morally wrong, Hero would not be forced to bear the distributive burdens of his disadvantage under Eyal's account. Shlomi Segall, like Eyal, highlights the relevance of normative expectations in individuals' acts and omissions. ${ }^{41}$ Considerations about what is reasonably avoidable matters, as well as whether it is reasonable for society to hold individuals to such a standard. Applied to the discrimination objection, the unacceptable implications of the standard luck egalitarian account can be blocked by the fact that disclosing one's sexual orientation is not a culpable choice (i.e. Eyal's standard) or it is not a reasonable normative expectation to demand of an agent not to disclose his sexual orientation (i.e. Segall's standard), and therefore not subject to luck egalitarian evaluation at the bar of justice.

There are some outstanding issues with these two accounts, such as what counts as a morally wrong choice or what the normative expectations ought to be. The issue of normative expectations is especially relevant to the discrimination objection. Consider, for example, defining reasonable avoidability by some majoritarian standpoint: $\mathrm{Z}$ is not reasonably avoidable because the majority of people do $\mathrm{Z}^{42}$ If this kind of majoritarian reasoning is given, then it does not take long to see how it may be an issue for responding to the discrimination objection, where the minority's act may be seen as contravening the majority's conception of reasonableness. I am not claiming that this is an insurmountable challenge for Segall, but it shows the importance of further normative input into a concept like reasonable avoidability.

The general approach from Eyal and Segall, then, can be seen as a promising template for integrating other normative principles into the general theory. The contribution of my constructive account, however, is to show that the consideration of many morally relevant facts (including culpability, in Eyal's terms, or normative expectations in Segall's terms) is built directly into the luck egalitarian framework. In short, it is not about 'modifying' luck egalitarianism so much as being cognisant of the Fact of Inherent Normativity which I will go on to highlight.

Another promising account in this category is Stemplowska's later work on reconciling the values of responsibility and respect through what we can call the balancing view. ${ }^{43}$ Because of the need to treat people as equal moral agents, the balancing view suggests that a balance should be struck between the costs of providing insurance with the costs of restricting people's interests in having to avoid that disadvantage:

\footnotetext{
40 Eyal, "Egalitarian Justice and Innocent Choice," 6.

41 Shlomi Segall, Health, Luck, and Justice (New Jersey: Princeton University Press, 2009), 19-21; Shlomi Segall, "Health, Luck and Justice Revisited," Ethical Perspectives 19, no. 2 (2012): 277-334.

42 We can think of $\mathrm{Z}$ as driving a car, for example, which may not be reasonably avoidable despite the risk it brings due to its significance to a huge majority of people.

43 Zofia Stemplowska, "Responsibility and Respect: Reconciling Two Egalitarian Visions," in Responsibility and Distributive Justice edited by Carl Knight and Zofia Stemplowska (Oxford: Oxford University Press, 2011), 115-135.
} 
“...people should be provided with insurance against a given type of avoidable disadvantage just as long as the interests that are served by not needing to avoid a given conduct (lest it leads to a disadvantage), or not needing to purchase private insurance against the disadvantage, outweigh the interests that would be served if such compensation did not have to be provided."

As Stemplowska herself readily acknowledges, however, the balancing response is not able to respond to many cases of the harshness or discrimination objections. The balancing response would not apply to cases of abandonment where the activity is seen as trivial or not outweighing the other arm of considerations, such as in the case of the uninsured bungee jumper or drunk driver. ${ }^{44}$

Stemplowska's balancing response, similar to Eyal's culpability move and Segall's normative expectations view, are what we might crudely call moralised responses in that they acknowledge the importance of thicker normative standards than the mere option/brute luck distinction in evaluating actions and their resulting disadvantages. This category of responses, I believe, provides the most plausible starting template for luck egalitarians to respond to the harshness and discrimination objections. My constructive account, intended as a preliminary sketch, develops their considerations further and incorporates insights from various luck egalitarian responses into a coherent framework to respond more fully to the harshness and discrimination objections.

\section{Two-Level Luck Egalitarianism}

The outstanding issues identified in this paper so far are as follows: First, the harshness and discrimination objections are important challenges in need of a response. Second, the available responses to the objections are generally either inadequate at meeting the harshness and discrimination objections, or the responses are adequate, but only at the expense of luck egalitarian principles. In what follows, I hope to establish that luck egalitarianism is a morally 'thick' theory, with its existing principles already relying upon a host of independent ethical and normative commitments. I will outline a two-level theory of luck egalitarianism that separates the distribution of fundamental rights and basic needs (the first level) from the distribution of more general and less fundamental goods (the second level). Distribution at the first level is de facto not sensitive to responsibility, while distribution at the second level is. The account is intended as a preliminary sketch that incorporates important insights from various luck egalitarian responses.

I will begin with a general claim that I will not defend at length. A plausible egalitarian theory of justice must uphold - alongside equality - the values of respect, responsibility, and rights. This view finds support in Ronald Dworkin's writings, who suggests that distributive justice is about finding "a solution that respects both the

\footnotetext{
44 Stemplowska states that "...this would still not lead us to offer compensation to those whose disadvantage is the result of drunk driving or going bungee jumping uninsured." Ibid., 129. The balancing account may thus be too narrow, in the sense that it is based merely on the relative costs of avoidability versus compensation, rather than being motivated by more normatively stable considerations.
} 
reigning principles of equal concern and personal responsibility... in a way that compromises neither principle but rather finds attractive conceptions of each that fully satisfy both." ${ }^{45}$ I shall argue that when we combine the principles of respect, responsibility, and rights, what we get is something akin to the two-level model I propose.

Two-level luck egalitarianism proposes that the distribution of basic needs and basic rights be different, in practice, to the distribution of less fundamental benefits and burdens. I emphasise in practice because, in theory, both tiers are governed by the same principles of rights, respect, and responsibility. The divergence in the practice and theory of two-level luck egalitarianism stems from what John Rawls calls the two concepts of rules.$^{46}$ According to Rawls' account, the rules that govern the justification or creation of a rule or institution is different to the rules that ought to govern practices that fall within that same rule/institution. I will elaborate further on this substantive point in the subsequent segment, but I will outline first the general principles of the two-level theory.

The first level (or first tier) of this account is concerned with the distribution of basic needs and basic rights. ${ }^{47}$ In practice, these goods are responsibility-insensitive except under very exceptional circumstances. Amongst these, we should include fundamental rights such as the right to equality before the law, to have one's basic needs met, to bodily integrity, to liberty, and to education. I defend why these rights should be responsibility-insensitive in the latter part of the paper. The second/tier is concerned with the distribution of all other benefits and burdens in society, including economic benefits over and above the threshold of first-level goods. Such goods could include economic and material wealth, and general happiness, for instance. The distribution of these goods is responsibility-sensitive, unlike those goods captured by the first level. The principles of rights and respect, however, must be considered even at this level. Stemplowska, Tan, and Dworkin's accounts highlight this important intuition, even if they do not articulate it explicitly in their work. ${ }^{48}$ Basic rights, such as the right to equality before the law, are inviolable rights regardless of recklessness and responsibility, while non-basic rights, such as the 'right' to economic prosperity are less binding and may be responsibility-sensitive.

\footnotetext{
45 Ronald Dworkin, Justice for Hedgehogs (Cambridge: Harvard University Press, 2011), 3, emphasis my own. See also: Ronald Dworkin, Taking Rights Seriously (Cambridge: Harvard University Press, 1977). In outlining his theory of resource-based egalitarianism, Dworkin also says: "My arguments enforce rather than construct a basic design of justice, and that design must find support, if at all, elsewhere than in those arguments" in Ronald Dworkin, "What Is Equality? Part 2: Equality of Resources," Philosophy and Public Affairs, 345.

46 John Rawls, "Two Concepts of Rules," The Philosophical Review 64, no. 1 (1955): 3-32.

${ }^{47}$ The exact criteria for inclusion in the first level may be subject to further debate, which I acknowledge. This openness, however, need not affect the overall plausibility of my preliminary account at this stage.

${ }^{48}$ Dworkin stipulates a number of conditions and assumptions about the creation of the hypothetical insurance market - for example, that all parties are accorded equal respect and have equal moral standing during the hypothetical auction. See: Ronald Dworkin, Sovereign Virtue: The Theory and Practice of Equality (Cambridge: Harvard University Press, 2000). Stemplowska emphasises the importance of respect in later works: Stemplowska, "Responsibility and Respect: Reconciling Two Egalitarian Visions," in Responsibility and Distributive Justice edited by Knight and Stemplowska.
} 
The responsibility-insensitivity criterion in the first level can be breached only in cases of absolute scarcity, or if there are very strong morally-defensible reasons to the contrary. For example, in a time of absolute scarcity, considering personal responsibility as a 'tie-breaker' may be a fairer way of distributing resources than pure responsibility-insensitive equality. Similarly, if there are very strong consequentialist reasons to breach the anti-responsibility thesis of first-level goods, we may have justification to do so. Even if rights are considered generally inviolable and responsibility-insensitive, it does not mean that they must be upheld at all costs. In any given society - even in conditions of moderate scarcity - some distributive actions intended to uphold rights and basic needs will come at too high a cost to society.

Consider a well-known concept from the bioethics literature known as the rule of rescue'. ${ }^{49}$ The rule of rescue refers to a psychological predisposition to save identifiable individuals in dire straits at any cost, often at the expense of other unidentifiable individuals. ${ }^{50}$ It is accepted amongst many medical ethicists and philosophers that prohibitively expensive treatment and 'rescues' should not be performed if the opportunity costs of doing so would harm many others by depriving them of care, even if this results in the death of the person in need of rescue. ${ }^{51}$ Even with a responsibility-insensitive first level, the two-level theory is not committed to performing any and all distributive measures to secure these basic needs and rights. The person may therefore be denied assistance, not on the basis of their responsibility/voluntariness, but on the basis that to rescue them would come at too great a harm to others in the society.

Despite the fact that first-level goods are not sensitive to responsibility in a practical sense, the account is still luck egalitarian in nature. The reason that goes into justifying such an approach is still motivated, albeit not solely, by the concept of responsibility. Guaranteeing the provision of first-level goods is, firstly, necessary for the satisfaction of rights and respect considerations. Upholding the principles of rights and respect, I stipulated at the start, are two of the three fundamental aspects of an egalitarian theory of justice. Secondly, first-level goods are often necessary conditions and prerequisites for the exercise of responsibility. Without firstlevel goods being satisfied, the exercise of human agency and responsibility may be hindered. This is because luck egalitarian theories of justice are committed to at least a pragmatic view of free will and agency. That is to say, luck egalitarians are committed to the Kantian maxim that ought implies can. ${ }^{52}$ Without a threshold of

\footnotetext{
49 Albert R. Jonsen, "Bentham in a Box: Technology Assessment and Health Care Allocation," The Journal of Law, Medicine and Ethics 14, no. 3-4 (1986): 172-174; and John McKie and Jeff Richardson, "The Rule of Rescue," Social Science and Medicine 56, no. 2 (2003): 2407-2419.

50 Richard Cookson, Christopher McCabe, and Aki Tsuchiya, "Public healthcare resource allocation and the Rule of Rescue," Journal of Medical Ethics 34, no. 7 (2008): 540-544.

51 Greg Bognar and Iwao Hirose, The Ethics of Health Care Rationing (Oxford: Routledge, 2011); and Nir Eyal, "Luck Egalitarianism, Harshness, and the Rule of Rescue," in Current Controversies in Bioethics edited by Matthew Liao and Colin O’Neill (London: Routledge, 2016).

52 Immanuel Kant, Critique of Pure Reason translated by Norman Kemp Smith (London: 1993), 637 [A807/B835]; and Immanuel Kant, The Metaphysics of Morals translated by Mary Gregor (Cambridge: Cambridge University Pres, 2017), 6:380.
} 
all-purpose goods and capabilities, such as access to education or the ability to act with liberty, human agency may not be possible. If human agency is not possible, in a pragmatic sense, then luck egalitarianism cannot proceed any further.

For luck egalitarianism to be able to judge an action as sufficiently voluntary and therefore appropriate to hold the agent accountable for the distributive outcomes of their choices, certain background conditions about agency must be met. Amongst these, we might include freedom from coercion, the presence of reasonable alternatives and choices, and access to adequate information. ${ }^{53}$ The rights and goods captured by the first level are themselves necessary to meet these minimal conditions for a voluntary action to be fairly attributed to an agent. Part of the rationale for prioritising first level goods, then, is explicitly luck egalitarian in nature. Without those first-level goods (at least as a guarantee in the beginning), the pro-responsibility thesis of luck egalitarianism may collapse, because it would transpire that no one can be reasonably held responsible for the outcomes of their actions. On the other hand, guaranteeing first-tier goods actually strengthens the plausibility and reasonableness of luck egalitarianism's pro-responsibility thesis. The responsibility-insensitive nature of first-tier goods, then, is grounded not only on the values of rights and respect, but on explicitly luck egalitarian considerations.

It may be said that, granting all the above conditions, why does this mean that those goods still have to be responsibility-insensitive once we give people an adequate initial share? That is, why not adopt a starting-gate theory of basic needs, such that we guarantee everyone an initial bundle of these goods, but make its retainment contingent upon their responsible actions? At this point, the Rawlsian concept of rules to justify theory/institutions versus rules in practice can be advanced. This philosophical approach is encapsulated in Rawls' influential defence of what he calls 'two concepts' of rules. ${ }^{54}$ The justificatory reasons we use to defend the of a rule or institution can be 'kicked away' when the time comes for that principle to be applied. According to Rawls, there is a "distinction between the justification of a practice and the justification of a particular action falling under it." 55

The justification for this so-called two concepts of rules is based on the kinds of considerations available to those justifying the practice in the first place versus those evaluating a particular action under that practice. At the time we construct an institution or rule, we generally have more time and information at our disposal to design how that institution should guide individual actions that fall under that practice. On the other hand, when evaluating individual acts, we generally have less time and information, and are more likely to get our judgements wrong unless we abide by rules established by prior deliberation. ${ }^{56}$ Applied to two-level luck egalitarianism,

\footnotetext{
53 The question about what kind of structural equality and 'equality of options' is necessary before we can judge an action as sufficiently voluntary is an ongoing debate. See, for instance, Johann Go, "Structure, Choice, and Responsibility," Ethics and Behavior 30, no. 3 (2020): 230-246.

54 Rawls, "Two Concepts of Rules," 16.

55 Rawls, "Two Concepts of Rules," 16.

56 This is reminiscent of a rule utilitarian approach. Utilitarian principles may go into the establishing of certain rules, but after these rules are created, acts are evaluated independently of the original utilitarian considerations. See, for example: Brad Hooker, Ideal Code, Real World: A Rule-Consequentialist Theory of Morality (Oxford: Oxford University Press, 2000).
} 
the principles of responsibility and agency (together with the consideration of other morally relevant principles) go into the justification for a non-responsibility sensitive first level. Once we establish that basic needs and rights are demanded by the practice of human agency and responsibility, together with the cardinal values of rights, respect, and responsibility, we may then not appeal directly to such considerations at the level of practice. However, considerations of responsibility (together with rights and respect) nonetheless strongly ground the first-level goods being responsibilityinsensitive at the level of practice. ${ }^{57}$

Those not convinced by Rawls' two concepts of rules, however, need not abandon my two-level theory. Another independent justificatory reason, which may appeal especially to existing luck egalitarians, is available. Built into every luck egalitarian account is a zone for the normative evaluation of other morally relevant factors. It is within this zone, for example, where we can consider a range of ethical and normative political principles to inform how we ought to respond, as a luck egalitarian theory, to individuals' voluntary acts/omissions. I shall call this the Fact of Inherent Normativity, which refers to the idea that any luck egalitarian account must inevitably draw upon a host of independent ethical factors, and that this is entirely consistent with a luck egalitarian framework. Serena Olsaretti argues that luck egalitarians need principles to determine what consequences are appropriate for each action, which she calls the principle of stakes ${ }^{58}$ For example, we may stipulate a principle that luck egalitarianism should, for all intents and purposes, never breach first level goods as a form of punishment. I use the term Fact of Inherent Normativity instead of Olsaretti's principle of stakes, because I am concerned not just with deliberation about the consequences for responsible acts, but with wider moral ideas that inevitably influence luck egalitarian theories overall.

The Fact of Inherent Normativity is what enables the luck egalitarian to consider rights and responsibilities, as well as consequences and other morally relevant factors, in a manner that remains consistent with the overall theory. A person who commits an action, Y, may be liable for a consequence, $Z$. The relationship between $\mathrm{Y}$ and $\mathrm{Z}$, however, is not some kind of a priori natural relationship. For example, assume $\mathrm{Y}$ is the act of being late to a meeting. Given $\mathrm{Y}$, what should follow for $\mathrm{Z}$ ? The answer is, it is not clear at all without (a) more context about the situation, and (b) an independent normative evaluation of the agent's action in light of the context. Here is a more detailed example. Assume that the action (Y) is being late to a meeting with one's social welfare case worker. What should the consequence $(Z)$ be now? Withdrawal of all social welfare benefits? Reduction of benefits by $50 \%$ ? A verbal and written warning? The answer is not something that can be derived from $\mathrm{Y}$ via some kind of self-evident moral relationship; it requires independent normative evaluation.

Another aspect of the Fact of Inherent Normativity is the fact that a luck egalitarian theory of justice must inevitably judge what constitutes voluntariness and

\footnotetext{
57 This grounding need not be absolute, however, as I go on to discuss in cases of serial negligent actors.

58 Serena Olsaretti, "Responsibility and the Consequences of Choice," Proceedings of the Aristotelian Society 109, no. 2 (2009): 165-188, at p. 1.
} 
responsibility. It is possible, for example, to never get injured in a car accident by never leaving the house. Whether or not this is reasonable matters, and a luck egalitarian can take this into account by considering a number of normative principles such as liberty and other rights. ${ }^{59}$ Yet another aspect to consider is what metric or currency of justice we ought to adopt. The debate and literature on this topic alone are enormous and attempting to deal with this aspect is beyond the scope of this paper. ${ }^{60}$ I will, however, make another preliminary stipulation: The most plausible metric of justice must be one that is pluralistic in nature and one that takes into account the incommensurability of certain individual metrics. I do not think that a purely resource-based metric of justice, for example, adequately upholds the principles of rights, respect, and equal concern. Recall the gay man who is deprived of his economic resources and opportunity to be Deputy CEO because of homophobic attitudes. This is arguably unfair and unjust, but it is not unfair simply because of the lost economic resources. It is more fundamental than this and involves a violation of the respect he is entitled to qua person. To consider the injustice simply a matter of unjust resource distribution would be to commit a moral error that overlooks the respect and rights he is owed. A plausible metric of justice, then, must consider a wide range of resources, welfare, opportunities, and capabilities, and provide a method for balancing incommensurable goods. The Fact of Inherent Normativity gives us scope to undertake these considerations consistently within a luck egalitarian framework.

Luck egalitarianism, understood in this 'thick', normatively-loaded way, leaves a lot of scope for independent normative judgements to enter the equation. It enables us to advance a two-level theory because this is what we derived from an independent ethical assessment justified and mandated by the Fact of Inherent Normativity. It justifies a pluralistic metric because we drew on a host of other morally relevant considerations in the application of the Fact of Inherent Normativity. While some aspects of my account may be reminiscent of Tan's domain response, they differ in important ways. The main difference is that $\mathrm{I}$ do not consider the first tier to be a matter of 'humanitarianism' or charity rather than distributive justice. This is a view Tan asserts without really defending, and such a radical re-conceptualisation of distributive justice is in need, at least, of some justification. The first level of my account is where some of the most fundamental benefits and burdens in society are distributed and, for this reason, must be central to any account of justice. My account acknowledges this, while justifying the separation of the two levels based on luck egalitarian principles, such as responsibility and agency. The other major difference is that my account is luck egalitarian throughout, rather than just at the

\footnotetext{
59 For a discussion on how luck egalitarianism ought to take into account reasonable avoidability, see: Gideon Elford, "Equality, Choice, and Alternatives: Why Reasonable Avoidability Matters," Ethical Perspectives 19, no. 3 (2012): 445-468; Gideon Elford, "The Symmetry of Responsibility," Journal of Social Philosophy; Segall, "Health, Luck, and Justice Revisited"; and Peter Vallentyne, "Brute Luck, Option Luck, and Equality of Initial Opportunities," Ethics 112, no. (2002): 529-557.

${ }^{60}$ See, for example: G. A. Cohen, On the Currency of Egalitarian Justice and Other Essay edited by Michael Otsuka (New Jersey: Princeton University Press, 2011); and Amartya Sen, "Equality of What?" The Tanner Lecture on Human Values. Delivered at Stanford University, May 1979.
} 
level above sufficiency. The Fact of Inherent Normativity adds a pluralist dimension to luck egalitarianism without having to advance independent constraints on luck egalitarian principles.

\section{1 (Re)Addressing the Harshness and Discrimination Objections}

Having articulated a preliminary sketch of the plausibility of a two-level theory of luck egalitarianism, I now briefly demonstrate how it enables us to address the harshness and discrimination objections better than existing accounts. In terms of the harshness objection, many of our intuitive objections can be addressed by considering the principles encapsulated in the first level of my account. Anderson's uninsured motorist has certain basic needs and rights guaranteed to him regardless of whether he is responsible for his actions or not. The justification for this is twofold: first, drawing on a Rawlsian distinction between the justification of a rule and the evaluation of individual acts that fall under that rule; and second, through the consideration of other morally relevant factors in accordance with the Fact of Inherent Normativity. This method enables us to uphold the motorist's rights and accord him respect, while being sensitive to principles of responsibility, even though these principles of responsibility operate at the meta-level of justifying the institution rather than at the stage of evaluating the act.

Suppose, however, that the uninsured motorist crashes his car again, and again. Would the two-level account mandate that the state continue to provide him with expensive assistance again and again, on the basis of the responsibility-insensitive nature of first-level goods? The answer, it seems to me, is no. Rights are not the only relevant consideration in a plausible egalitarian theory of justice. Responsibility and respect are also part of the equation. When designing the institution of the two-level theory, we need an account of how to deal with serial negligence and recurrent irresponsible actions. Such an account would arguably impose some kind of limit to how much assistance a state should give those who recurrently partake in negligent acts that affect others. To deprive social resources for others through one's recurrent negligent acts would be to disrespect others' prudence and agency. The consideration of consequences is also relevant in designing the two-level account. While basic needs and rights should be guaranteed as far as possible, we should be aware of the third-party impacts of rescuing the negligent person again and again. Such effects could include worsening the incidence of moral hazard, due to people's perception that they would be protected for any actions, and violating the rights of the prudent majority.

An internal tension may arise, however, given my claim that first level goods are often prerequisite for acting responsibly. ${ }^{61}$ The tension arises as a result of my biting bullet for recurrent negligent victims. It could be claimed that biting the bullet for serial negligent victims is in tension with the role first-level goods play as

${ }^{61}$ I thank an anonymous reviewer from this journal for pressing me on this important tension. 
prerequisite conditions for responsibility. In response, it is important to note that the prerequisite justification for separating first-level from second-level goods is not the only justification for the two-tier account. The values of rights and respect, together with responsibility, provide the main scaffold. Our acceptance of the twolevel account, therefore, need not necessarily depend on fully accepting the prerequisite justification. Once the tripartite cardinal values are considered in their totality in the justification of the first level (rather than just focussing on responsibility), the internal tension is diffused.

This account remains loyal to Rawls' two concepts of rules, because these judgements about what to do with serial negligence is incorporated into the design of the institution/rule rather than being made on an act-by-act basis. ${ }^{62}$ At the same time, it is distinctly luck egalitarian. It ultimately agrees with Stemplowska's judgement about the mountain climber in need of rescue, for instance, though it grounds this justification in a broader consideration of responsibility and egalitarian justice. I must emphasise, however, that this is not a simple 'bite the bullet' response at the harshness objection. What makes Anderson's harshness objection so powerful is because we are leaving the negligent person in dire straits on the basis of just one mistake i.e. the one time Bert crashes. When the scenario becomes one of serial negligence and the continued perpetuation of disrespect and harm to others, the power of the harshness objection is diminished. My biting the bullet for this scenario is therefore not comparable to biting the bullet for Anderson's harshness objection.

In terms of the discrimination objection, we have two possible options. First, we may accept that freedom from homophobic discrimination is constitutive of the right to equality before the law or freedom of expression. Therefore, this falls under the basic rights guaranteed by the first level of the theory, and so is responsibilityinsensitive. Second, we may very reasonably hold the view that a consideration of the tripartite egalitarian values of rights, respect, and responsibility means that we ought not to hold the gay man responsible for the distributive effects of his voluntary choices given that this was exercised under his right to free expression, and on the understanding that holding him responsible would be contrary to the principle of respect. Third, we may appeal to ethical considerations performed under the auspices of the Fact of Inherent Normativity to better understand how we ought to judge the situation of disadvantaging oneself through a voluntary act of disclosing one's sexuality. Luck egalitarianism, as I discussed, must inevitably be informed by a cornucopia of moral considerations. One of these moral considerations is a judgement about which actions should even fall within the purview of luck egalitarian evaluation. Drawing on our considered judgements and ethical principles, disclosing one's sexuality is not grounds for luck egalitarianism's distributive consideration. The value we attach to live as we wish, as long as we do not harm others, is a vital moral consideration that should inform our luck egalitarian theory. ${ }^{63}$ This concept of pluralism can be built into luck egalitarianism itself, through the Fact of Inherent Normativity. Together with the other cardinal values of rights and respect, luck

62 Rawls, "Two Concepts of Rules," 16.

63 John Stuart Mill, On Liberty edited by Gertrude Himmelfarb (London: Penguin, 1982). 
egalitarian's focus on responsibility, understood through my two-level account, enables it to be a candidate for a very plausible theory of justice.

\section{Conclusion}

Luck egalitarianism is a theory of justice with a lot of intuitive appeal and philosophical plausibility, though also one that has been subjected to a barrage of criticism. I have offered an initial outline of a possible refinement to make luck egalitarian more acceptable as a theory of distributive justice. Understood as a two-level theory informed by the cardinal values of rights, respect, and responsibility, luck egalitarianism can provide plausible guidance on distributive justice while not falling prey to the harshness and discrimination objections. The justifications I have offered in support of the two-level approach are compatible with fundamental luck egalitarian principles of responsibility and agency. First, luck egalitarianism should be understood as a morally 'thick' theory, which necessitates the input of independent ethical principles at several points of the theory to make it coherent - the Fact of Inherent Normativity. The existence of this inherent normativity makes luck egalitarianism an inevitably pluralistic theory of distribution, allowing us to respond to the harshness and discrimination objections with responsibility-independent constraints within a consistent luck egalitarian framework. Second, Rawls' two concept of rules gives us a plausible philosophical justification to apply luck egalitarian principles differently in the establishment of the theory and in the practice of individual acts within that same theory. The luck egalitarian considerations of agency and responsibility that justify the salience of basic needs in the first level of the theory, therefore, need not be advanced directly in the evaluation of specific voluntary acts that activate those same principles in practice. Third, a theory of egalitarian justice that combines the three cardinal values of rights, respect, and responsibility can remain distinctively luck egalitarian. Far from being a counter-intuitive and implausible theory of justice, two-level luck egalitarianism can align with our considered judgements and existing normative commitments.

Acknowledgements I am grateful to Zofia Stemplowska for helpful comments and discussion, and to the anonymous reviewers from this journal for several rounds of instructive and critical comments.

Open Access This article is licensed under a Creative Commons Attribution 4.0 International License, which permits use, sharing, adaptation, distribution and reproduction in any medium or format, as long as you give appropriate credit to the original author(s) and the source, provide a link to the Creative Commons licence, and indicate if changes were made. The images or other third party material in this article are included in the article's Creative Commons licence, unless indicated otherwise in a credit line to the material. If material is not included in the article's Creative Commons licence and your intended use is not permitted by statutory regulation or exceeds the permitted use, you will need to obtain permission directly from the copyright holder. To view a copy of this licence, visit http://creativecommons.org/licen ses/by/4.0/.

Publisher's Note Springer Nature remains neutral with regard to jurisdictional claims in published maps and institutional affiliations. 